\title{
Hypolignification: A Decisive Factor in the Development of Hyperhydricity
}

\author{
Nurashikin Kemat ${ }^{1,2, *(D)}$, Richard G. F. Visser ${ }^{1}$ (D) and Frans A. Krens ${ }^{1}$ \\ 1 Plant Breeding, Wageningen University and Research, P.O. Box 386, 6700 AJ Wageningen, The Netherlands; \\ richard.visser@wur.nl (R.G.F.V.); frans.krens@wur.nl (F.A.K.) \\ 2 Department of Agriculture Technology, Faculty of Agriculture, Universiti Putra Malaysia, \\ Serdang 43400, Malaysia \\ * Correspondence: nurash@upm.edu.my
}

Citation: Kemat, N.; Visser, R.G.F.; Krens, F.A. Hypolignification: A Decisive Factor in the Development of Hyperhydricity. Plants 2021, 10, 2625. https://doi.org/10.3390/ plants10122625

Academic Editor:

Iyyakkannu Sivanesan

Received: 24 September 2021

Accepted: 13 November 2021

Published: 29 November 2021

Publisher's Note: MDPI stays neutral with regard to jurisdictional claims in published maps and institutional affiliations.

Copyright: (c) 2021 by the authors. Licensee MDPI, Basel, Switzerland. This article is an open access article distributed under the terms and conditions of the Creative Commons Attribution (CC BY) license (https:/ / creativecommons.org/licenses/by/ $4.0 /)$.

\begin{abstract}
One of the characteristics of hyperhydric plants is the reduction of cell wall lignification (hypolignification), but how this is related to the observed abnormalities of hyperhydricity (HH), is still unclear. Lignin is hydrophobic, and we speculate that a reduction in lignin levels leads to more capillary action of the cell wall and consequently to more water in the apoplast. $p$-coumaric acid is the hydroxyl derivative of cinnamic acid and a precursor for lignin and flavonoids in higher plant. In the present study, we examined the role of lignin in the development of $\mathrm{HH}$ in Arabidopsis thaliana by checking the wild-types (Ler and Col-0) and mutants affected in phenylpropanoid biosynthesis, in the gene coding for cinnamate 4-hydroxylase, $\mathrm{C} 4 \mathrm{H}$ (ref3-1 and ref3-3). Exogenously applied $p$-coumaric acid decreased the symptoms of $\mathrm{HH}$ in both wild-type and less-lignin mutants. Moreover, the results revealed that exogenously applied $p$-coumaric acid inhibited root growth and increased the total lignin content in both wild-type and less-lignin mutants. These effects appeared to diminish the symptoms of $\mathrm{HH}$ and suggest an important role for lignin in $\mathrm{HH}$.
\end{abstract}

Keywords: Arabidopsis thaliana; apoplast; hyperhydricity; hypolignification; micropropagation; $p$-coumaric acid; piperonylic acid

\section{Introduction}

Hyperhydricity $(\mathrm{HH})$, refers to the abnormal growth that is observed in tissues grown in vitro in response to water availability from gelrite media, hormonal imbalance, and tissue culture conditions. This phenomenon causes changes in the plant system at both anatomical and physiological levels such as reduced number of palisade cell layers, irregular stomata, chloroplast degeneration, the presence of a thin cuticle or no cuticle at all, an unorganized spongy mesophyll with large intercellular spaces, long petioles, brittle, and translucent and curled leaves [1-5]. A hypothetical model which describes a sequence of reactions leading to $\mathrm{HH}$ and which integrates most of the available biochemical data has been published [6-8]. These reactions involving soluble phenols, basic and acidic peroxidases, and the metabolism of auxin and ethylene lead to a deficiency in cellulose and lignin which may explain the anatomical change and hence part of the morphological changes.

In higher plants, the cell wall is one of the first tissues affected by stress signals, which are then transmitted to the cell interior and influence several processes [9]. Lignins are complex cell wall phenolic heteropolymers covalently associated with both polysaccharides and proteins [10]. The deposition of lignins in the cell walls of higher terrestrial plants provides rigidity and structural support to the aerial axis. Lignin fills the spaces in the cell wall between cellulose, hemicellulose, and pectin components, especially in vascular and support tissues like xylem tracheids, vessel elements, and sclereid cells. The polysaccharide components of plant cell walls are highly hydrophilic and thus permeable to water, whereas lignin is more hydrophobic. Beyond the structural function, lignin plays several other important biological roles in plants. Because it is much less hydrophilic than cellulose and hemicellulose, it prevents the absorption of water by these polysaccharides in plant cell 
walls and allows the efficient transport of water in the vascular tissues. The crosslinking of polysaccharides by lignin is an obstacle for water absorption into the cell wall, thus allows for the efficient translocation of water and solutes over long distances within the vascular systems [11,12].

Lignin is a polymer formed by oxidative coupling of $p$-hydroycinnamyl alcohol monomers (monolignols), which are products of the phenylpropanoid pathway [13]. The phenylpropanoid pathway was key to this evolutionary transition, in that flavonoids and other phenylpropanoid derivatives provide protection from UV-induced DNA damage, and lignin provides structural support to both individual tracheary elements and the stem as a whole [14]. One of the major phenylpropanoid pathway end-products is lignin, a heteropolymer important for the mechanical strength and hydrophobicity of the plant secondary cell wall [15]. The first three biosynthetic reactions in phenylpropanoid metabolism are often referred to as the general phenylpropanoid pathway, because they produce $p$-coumaroyl $\mathrm{CoA}$, a major branch-point metabolite between the production of the flavonoids and the pathway that produces monolignols, lignans and hydroxy-cinnamate conjugates [4,5] (Figure 1). The first step in this pathway is the deamination of phenylalanine by phenylalanine ammonia-lyase (PAL) to produce cinnamate, which is the substrate for the cinnamate 4 -hydroxylase $(\mathrm{C} 4 \mathrm{H})$, that generates $p$-coumarate. The next step is hydroxylation at the 3-position of $p$-coumarate by $p$-coumarate 3-hydroxylase $(\mathrm{C} 3 \mathrm{H})$ to produce, in succession, caffeate, ferulate, 5-hydroxyferulate, and sinapate. By the sequential action of 4-coumarate: CoA ligase (4CL), cinnamoyl-CoA reductase (CCR), and cinnamyl alcohol dehydrogenase (CAD), these metabolites are converted into the corresponding monolignols. In the last step of the pathway, cell wall-bound peroxidase (POD) catalyzes the oxidative polymerization of the three $p$-hydroxycinnamyl alcohols ( $p$-coumaryl, coniferyl and sinapyl alcohols) that give rise to the $p$-hydroxyphenyl $(\mathrm{H})$, guaiacyl $(\mathrm{G})$, and syringyl (S) units of the lignin polymer, respectively $[16,17]$.

Phenylalanine

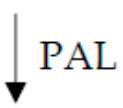

Cinnamic acid

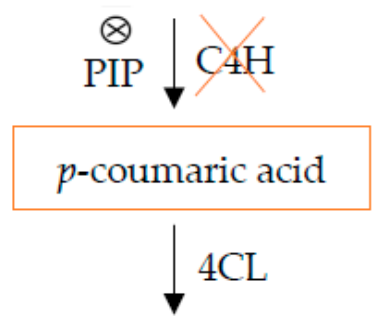

p-coumaroyl CoA

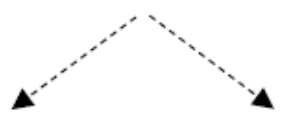

Flavonoids Monolignols, lignans, sinapate esters

Figure 1. The general phenylpropanoid pathway.

The gene encoding cinnamate 4-hydroxylase $(\mathrm{C} 4 \mathrm{H})$ was one of the first phenylpropanoid pathway genes to be cloned [6,7]. There is one copy of C4H in Arabidopsis [18]; thus, any carbon flux through phenylpropanoid metabolism is mediated by the activity of the protein encoded by this single gene. Expression of $\mathrm{C} 4 \mathrm{H}$ in Arabidopsis is apparent in seedlings soon after seed imbibition, and is observable in most organs during all stages of growth. This expression pattern was corroborated by microarray analysis [19]. The hydrox- 
ycinnamate ester sinapoylmalate plays an important role in UV protection in Arabidopsis thaliana [20]. Besides, the production of sinapoylmalate was localized in the leaf adaxial epidermis [21]. Sinapoylmalate serves as an excellent genetic marker for mutations in genes that are involved in phenylpropanoid metabolism because of its blue-green fluorescence under UV light [22]. Mutations that decrease the accumulation of sinapoylmalate lead to a reduced epidermal fluorescence ( $r e f$ ) phenotype that results from the red fluorescence of chlorophyll in the underlying mesophyll. The ref mutants derived from this screen have been instrumental in the isolation of a number of genes involved in phenylpropanoid metabolism $[14,23,24]$.

Arabidopsis ref3 mutants are characterized in that they constitute an allelic series bearing missense mutations in the gene encoding $\mathrm{C} 4 \mathrm{H}$, which failed to accumulate wildtype levels of sinapoylmalate [14,23]. The map positions for the REF3 gene were all consistent with the hypothesis that the ref3 mutation is within the gene encoding $\mathrm{C} 4 \mathrm{H}$. Molecular evidence showed that each mutant allele contained a single $\mathrm{G}$ to $\mathrm{A}$ transition, which results in a mis-sense mutation: GCG to ACG for ref3-1 (A306T), AGA for AAA for ref3-2 (R249K), and GGA to GAA for ref3-3 (G99E). The missense mutations found in the ref3 alleles were associated with an array of metabolic changes. In addition to having low levels of sinapoylmalate, leaves of the ref3 mutants accumulated at least two cinnamate esters that were not found in the leaves of wild-type plants [25]. Levels of condensed tannins in ref3 seeds were also reduced, and lignin deposition in each of the ref3 mutants was lower as well. The latter phenomenon appeared to be caused by a decrease in guaicyl (G) lignin monomers, leading to a syringyl/guaiacyl (S/G) ratio higher than that of the wild-type [14]. They found that the decrease was exclusively derived from a reduction in guaiacyl-derived subunit content leading to a substantial increase in the mole percentage of syringyl-subunits in the lignin of the mutant. These metabolic changes are likely due to the altered stability and substrate binding of the mutant $\mathrm{C} 4 \mathrm{H}$ proteins which all lead to amino acid substitutions in structural motifs that are highly conserved in the $\mathrm{C} 4 \mathrm{H}$ proteins of land plants. The reduction in lignin content in plants carrying the mutated alleles resulted in a collapsed xylem phenotype like those previously observed in other Arabidopsis mutants affected in lignin and cellulose biosynthesis [26,27].

$p$-coumaric acid is a hydroxyl derivative of cinnamic acid and a precursor for lignin and flavonoids in higher plant. Addition of hydroxycinnamic acid increases lignin production and inhibits shoot and root growth in pea [28], cucumber [29], canola [30], and soybean [31-33]. Piperonylic acid (PIP) is a quasi-irreversible inhibitor of the $\mathrm{C} 4 \mathrm{H}$ enzyme (Figure 1). Exogenously applied piperonylic acid (PIP) an inhibitor of $\mathrm{C} 4 \mathrm{H}$, gave a significant effect on lignin synthesis and lignin content in soybean [34]. Moreover, the effect of hydroxycinnamic acid in inhibiting root growth and increasing lignin has been described $[16,35,36]$.

The objective of this study was to investigate the role of lignin on $\mathrm{HH}$ development by looking at the relative amounts of apoplastic water and air to the total apoplast volume, root growth, total lignin content, $\mathrm{C} 4 \mathrm{H}$ activity, $\mathrm{C} 4 \mathrm{H}$ gene expression, and phenylalanine ammonia-lyase (PAL) activity, and at the anatomical structure of leaves in Arabidopsis thaliana wild-types (Ler and Col-0) and less-lignin mutants (ref3-1 and ref3-3).

\section{Results}

2.1. The Effect of p-Coumaric Acid on Apoplastic Water and Air Volumes in Arabidopsis thaliana Col-0 Seedlings

The physical and chemical state of the medium influence greatly plant development and $\mathrm{HH}$. Manifested mainly in the leaves, $\mathrm{HH}$ plants exhibit a higher content of water and lignin deficiency. Plants experiencing HH display translucent, wrinkled, or curled leaves, elongated petioles and look brittle. In comparison with $0.4 \%(w / v)$ gelrite alone (Figure $2 \mathrm{~B}$ ), the symptoms of $\mathrm{HH}$ (e.g., curled, glassy appearance, longer petioles) were reduced by adding $p$-coumaric acid to $0.4 \%(w / v)$ gelrite solidified media (Figure $2 \mathrm{C}$ ). The percentage of the apoplast water volume sharply declined from $59 \%$ to $38 \%$ and the percentage of the apoplast air volume increased from $42 \%$ to $62 \%$ by increasing the added amount of $p$-coumaric acid from 10 to $500 \mu \mathrm{M}$; the differences were even greater when comparing 
to $0.4 \%(w / v)$ gelrite (Figure 3). No difference was found between $100 \mu \mathrm{M}$ and $500 \mu \mathrm{M}$ $p$-coumaric acid for the volume percentages of apoplastic water and air. This shows that $100 \mu \mathrm{M}$ was the optimal concentration of $p$-coumaric acid in $0.4 \%(w / v)$ gelrite solidified media in reducing $\mathrm{HH}$.
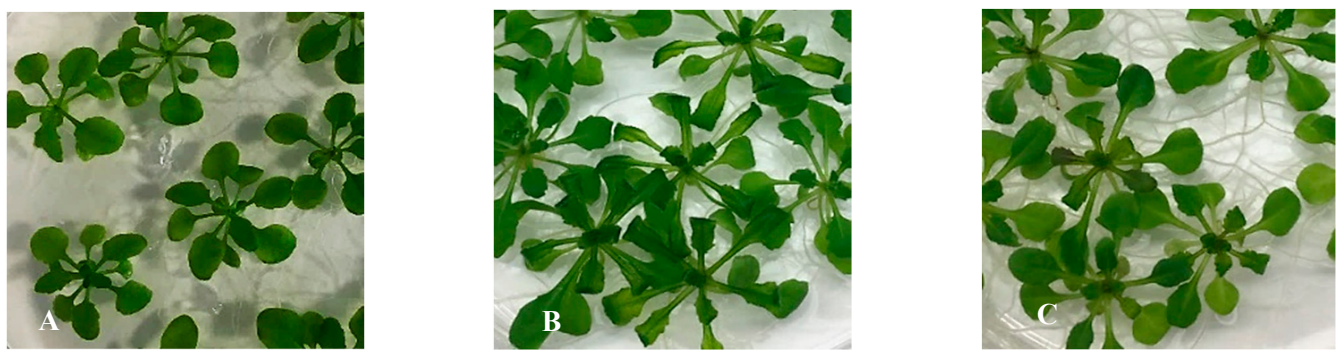

Figure 2. Phenotypic appearance of Arabidopsis thaliana Col-0 on $p$-coumaric acid at 14 days of culture. (A) Seedlings cultured on 0.7\% ( $w / v)$ Micro-agar (control), (B) Seedlings cultured on $0.4 \%(w / v)$ gelrite and $(\mathbf{C})$ Seedlings cultured on $0.4 \%(w / v)$ gelrite $+100 \mathrm{uM} p$-coumaric acid. Bar $=5 \mathrm{~mm}$.

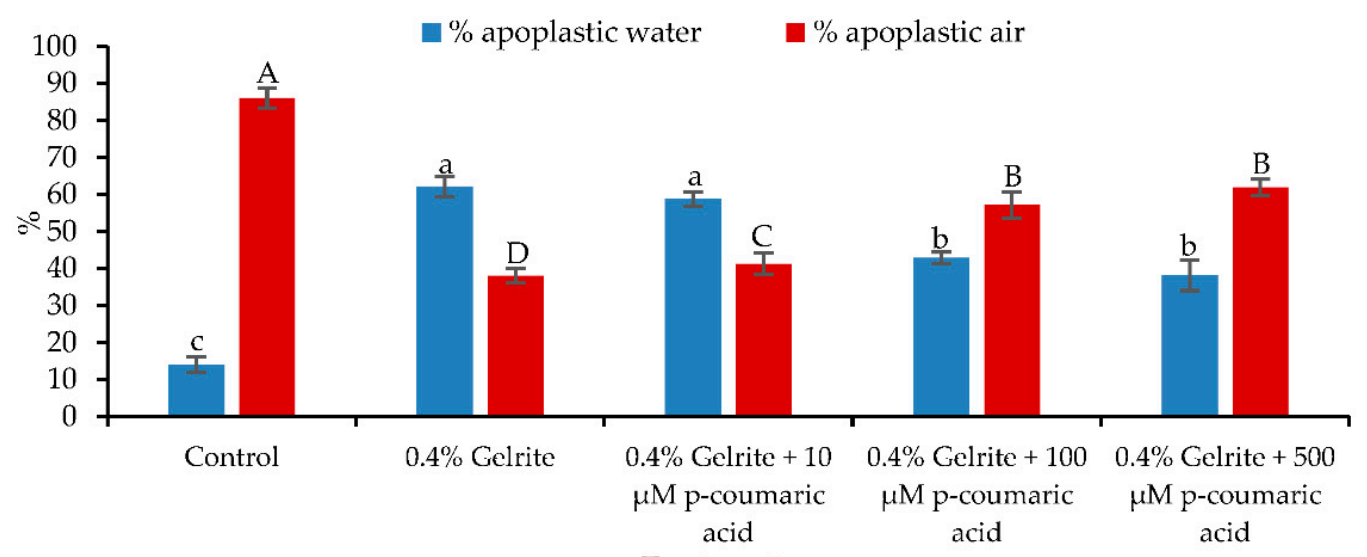

Figure 3. The percentages of apoplastic water and air related to the total volume of the apoplast in Arabidopsis thaliana (Col-0) seedlings after 14 days of culture on different concentrations of $p$-coumaric acid. Different letters indicate significant differences between means at $\alpha=0.05$ level.

\subsection{The Effect of -Coumaric Acid on Lignin Production and Root Growth Linked to the Development of $\mathrm{HH}$}

Phenotypic observations showed that both less-lignin mutant seedlings (ref3-1 and ref3-3) already on Micro-agar medium exhibited the symptoms of $\mathrm{HH}$ such as curled, elongated petioles, bigger leaves, and brittle leaves (Figure 4B,F). A similar response was found for ref3-1 and ref3-3 seedlings on $0.4 \%(w / v)$ gelrite medium (Figure $4 \mathrm{C}, \mathrm{G})$. These results suggested that lignin plays a role in $\mathrm{HH}$. These findings led us to investigate the effect of adding $p$-coumaric acid, the product of the $\mathrm{C} 4 \mathrm{H}$ enzyme, to less-lignin mutant seedlings on gelrite medium. Exogenously applied $p$-coumaric acid showed a decrease of the development of HH symptoms in both mutants (Figure 4D,H). Therefore, based on previous results, we determined the percentage of apoplast water and air volumes related to the total volume of the apoplast. The result showed that the percentage of apoplastic water decreased and the percentage of apoplastic air increased by adding the optimal concentration of $p$-coumaric acid at $100 \mu \mathrm{M}$ to $0.4 \%(w / v)$ gelrite medium (Figure 5). 

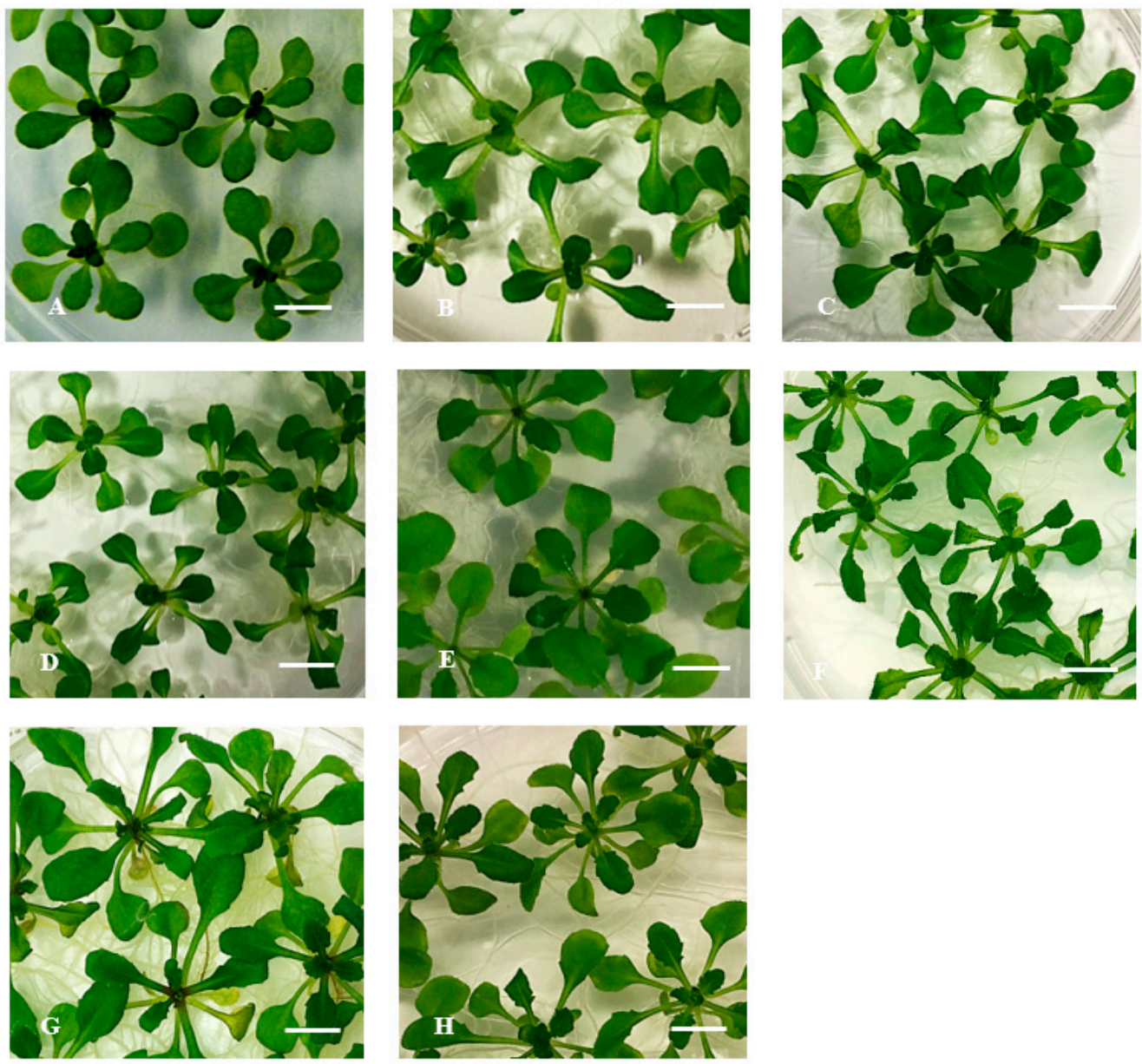

Figure 4. Development of $\mathrm{HH}$ on Arabidopsis thaliana less-lignin mutants ref3-1 and ref3-3 on $p$-coumaric acid after 14 days of culture. (A) Ler seedlings cultured on $0.7 \%$ Micro-agar (control), (B-D) ref3-1: (B) Seedling cultured on $0.7 \%(w / v)$ Micro-agar, (C) Seedling cultured on $0.4 \%(w / v)$ gelrite, and (D) Seedling cultured on $0.4 \%(w / v)$ gelrite $+100 \mu \mathrm{M} p$-coumaric acid. (E) Col-0 seedlings cultured on $0.7 \%$ Micro-agar (control), (F-H) ref3-3: (F) Seedling cultured on $0.7 \%(w / v)$ Micro-agar, (G) Seedling cultured on $0.4 \%(w / v)$ gelrite, and $(\mathbf{H})$ Seedling cultured on $0.4 \%(w / v)$ gelrite $+100 \mu \mathrm{M}$ $p$-coumaric acid. Bar $=5 \mathrm{~mm}$.

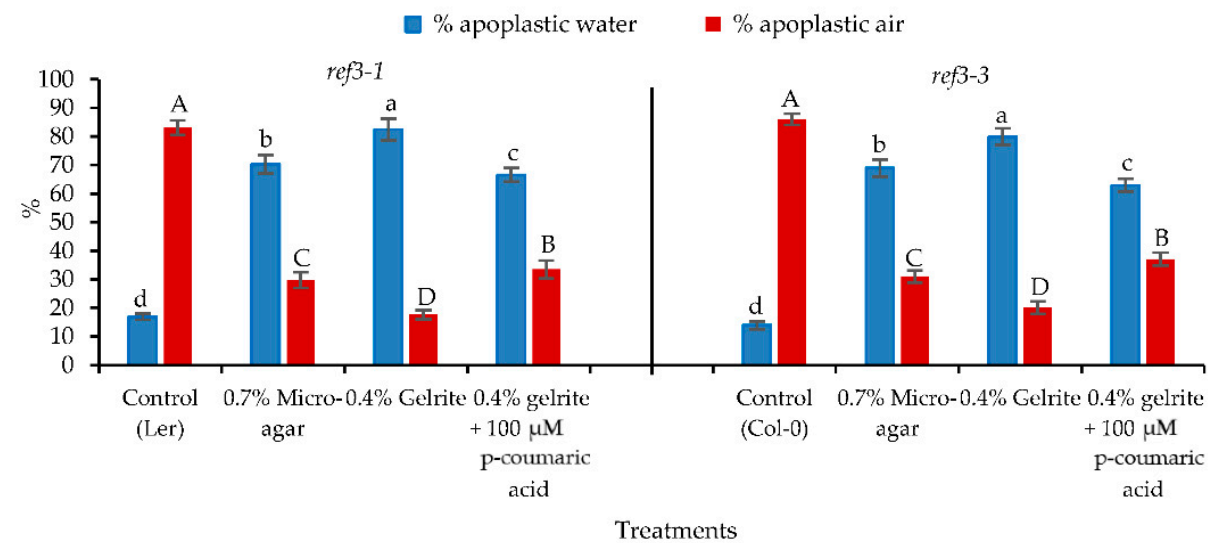

Figure 5. The percentages of apoplastic water and air related to the total volume of the apoplast in Arabidopsis thaliana less-lignin-mutant ref3-1 and ref3-3 seedlings after 14 days of culture on $0.7 \%(w / v)$ Micro-agar, $0.4 \%(w / v)$ gelrite and $0.4 \%$ gelrite $(w / v)+100 \mu \mathrm{M} p$-coumaric acid. Different letters indicate significant differences between means at $\alpha=0.05$ level. 
On top of the effect observed on the percentages of the water and air volumes, we studied further the total lignin content of the seedlings in these treatments. Seedlings exposed to $p$-coumaric acid significantly increased their total lignin levels in both wildtypes (Ler and Col-0) as well as in the mutants (ref3-1 and ref3-3) (Table 1). The total amount of lignin in hyperhydric Ler wild-type plants on $0.4 \%(w / v)$ gelrite did not significantly different from ref3-1 mutant on Micro-agar. The same applies to hyperhydric Col-0 plants where the amount of lignin was also very close to ref3-3 mutant on Micro-agar. Exogenously applied $p$-coumaric acid in both wild-type (Ler and Col-0) and mutant (ref3-1 and ref3-3) increased the total lignin content about $10 \%$ to $22 \%$ in the seedlings comparing to seedlings on $0.4 \%$ gelrite alone. This demonstrates that lignin plays an important role in reducing $\mathrm{HH}$ in Arabidopsis seedlings. Figure 6 showed the observations on the root growth of the seedlings on Micro-agar (control), $0.4 \%$ gelrite and $0.4 \%$ gelrite medium supplemented with $100 \mu \mathrm{M} p$-coumaric acid. The seedlings treated with $p$-coumaric acid showed a reduction in root growth (adventitious roots) in comparison with $0.4 \%$ gelrite alone (Figure $6 \mathrm{~B}, \mathrm{C}$ ).
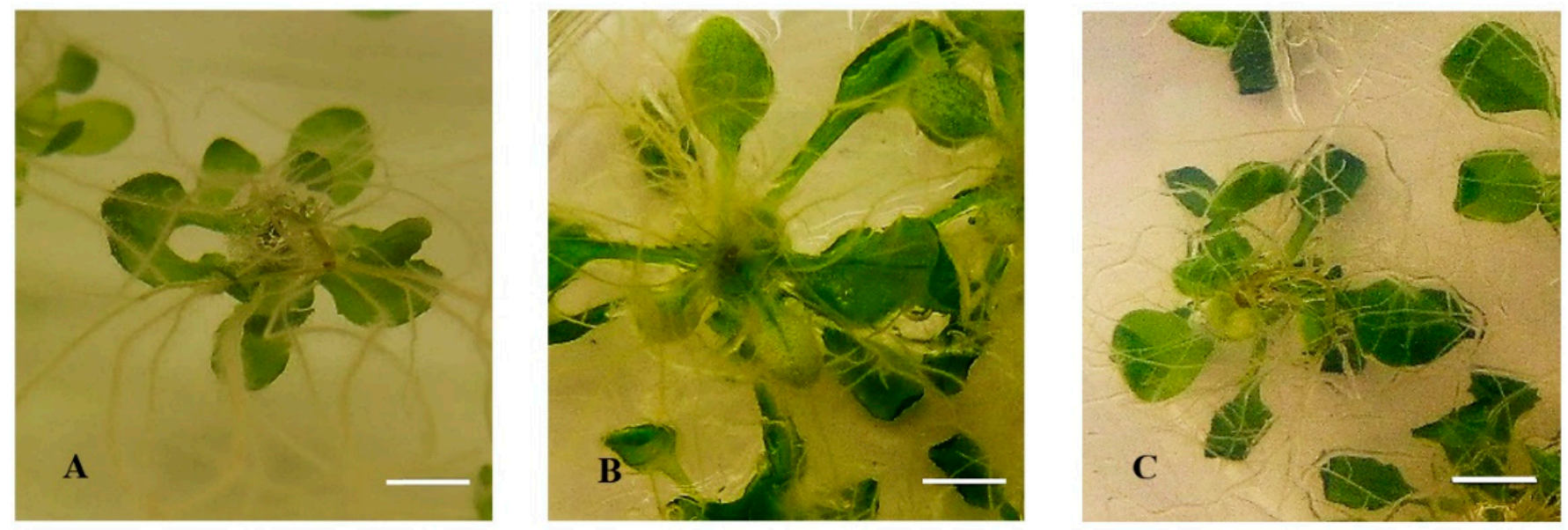

Figure 6. Morphological observations of root growth on Arabidopsis thaliana Col-0, and the less-lignin mutant (ref3-3). (A) Seedlings on Micro-agar (control), (B) Seedlings on $0.4 \%(w / v)$ gelrite, and (C) Seedlings cultured on $0.4 \%(w / v)$ gelrite $+100 \mu \mathrm{M} p$-coumaric acid. Bar $=5 \mathrm{~mm}$.

Table 1. Total lignin of Arabidopsis thaliana wild-type and less-lignin-mutant seedlings (Ler, Col-0, ref3-1, and ref3-3).

\begin{tabular}{|c|c|}
\hline Line & Lignin $\left(\mathrm{A}_{280} \mathrm{mg} \mathrm{g}^{-1}\right.$ Cell Walls $)$ \\
\hline Ler $0.7 \%$ Micro-agar (control) & $0.0182 \pm 0.0002^{\mathrm{a}}$ \\
\hline Ler $0.4 \%$ Gelrite & $0.0084 \pm 0.0006^{\mathrm{d}}$ \\
\hline Ler $0.4 \%$ Gelrite $+100 \mu \mathrm{M} p$-coumaric acid & $0.0123 \pm 0.0004^{b}$ \\
\hline ref3-1 Micro-agar & $0.0076 \pm 0.0006^{\mathrm{d}, \mathrm{e}}$ \\
\hline ref3-1 $0.4 \%$ Gelrite & $0.0067 \pm 0.0005^{\mathrm{e}}$ \\
\hline ref3-1 $0.4 \%$ Gelrite $+100 \mu \mathrm{M} p$-coumaric acid & $0.0102 \pm 0.0003^{c}$ \\
\hline Col-0 0.7\% Micro-agar (control) & $0.0225 \pm 0.0004^{\mathrm{a}}$ \\
\hline Col-0 0.4\% Gelrite & $0.0119 \pm 0.0002^{c}$ \\
\hline Col-0 $0.4 \%$ Gelrite $+100 \mu \mathrm{M} p$-coumaric acid & $0.0146 \pm 0.0007^{\mathrm{b}}$ \\
\hline ref3-3 Micro-agar & $0.0098 \pm 0.0003^{\mathrm{d}}$ \\
\hline ref3-3 $0.4 \%$ Gelrite & $0.0088 \pm 0.0003^{\mathrm{d}}$ \\
\hline ref 3-3 0.4\% Gelrite $+100 \mu \mathrm{M} p$-coumaric acid & $0.0138 \pm 0.0004^{b}$ \\
\hline
\end{tabular}

The means of 9 leaves \pm SE are presented; letters indicate significant differences between means at $\alpha=0.05$ level

\subsection{The Effect of Inhibiting Lignin Biosynthesis on $\mathrm{HH}$}

Having already ascertained that lignin and $\mathrm{HH}$ were affected by the addition of $p$-coumaric acid to the media and hypothesizing that $p$-coumaric acid (the product hydroxylation of cinnamic acid) can be channelled into the phenylpropanoid pathway leading to lignins via the $\mathrm{C} 4 \mathrm{H}$ reaction, the wild-type (Ler and Col-0) seedlings were treated with 
piperonylic acid (PIP) as an inhibitor of the $\mathrm{C} 4 \mathrm{H}$ enzyme. The objective was to confirm the role of lignin in $\mathrm{HH}$ and by using the inhibitor mimicking the effect and phenotype of the less-lignin mutants which were used in this study. Figure 7B,E showed that PIP added to Micro-agar medium triggered the development of $\mathrm{HH}$ on wild-type Ler and Col-0 of 14 days-old seedlings (Figure 7A,D). The seedlings showed the symptoms of HH; curled, elongated petioles, and brittle leaves. The seedlings looked very similar to less-lignin mutant ref3-1 and ref3-3 on Micro-agar medium (Figure 7C,F).
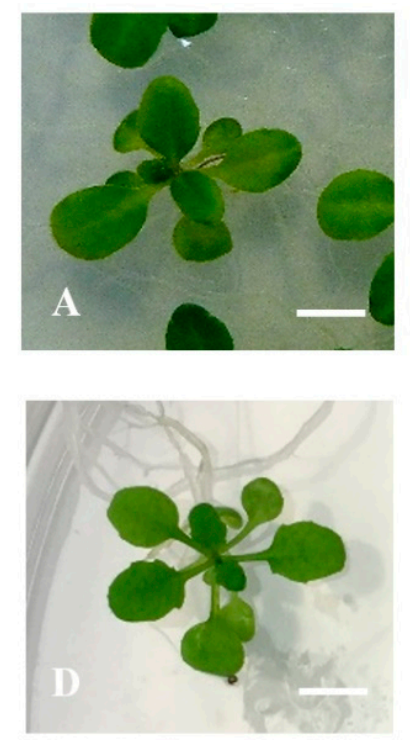
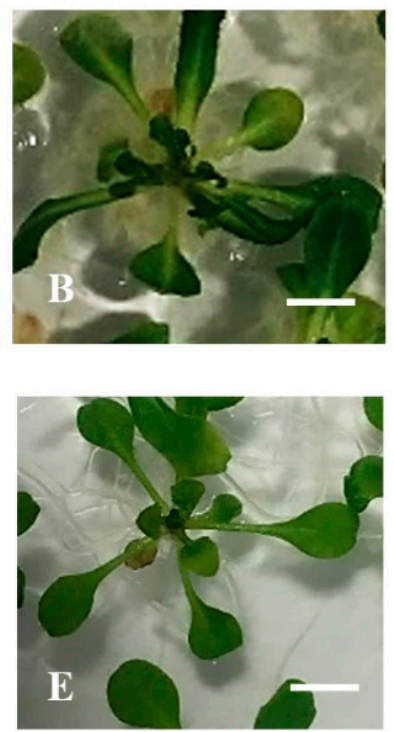
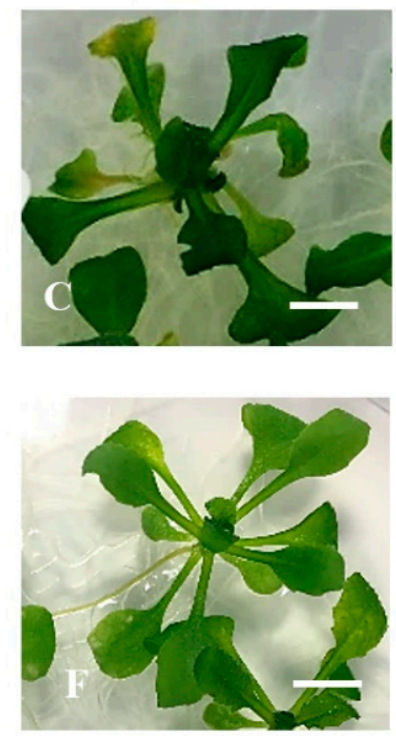

Figure 7. Phenotypic appearance of Arabidopsis thaliana Ler, Col-0, ref3-1, and ref3-3 seedlings after PIP treatment on $0.7 \%(w / v)$ Micro-agar (control). (A-C) Ler seedlings; (A) Cultured on Micro-agar (Control), (B) Cultured on $100 \mathrm{uM}$ PIP, (C) ref3-1 seedlings, (D-F) Col-0 seedlings: Cultured on Micro-agar (Control), (B) Cultured on $100 \mathrm{uM}$ PIP, and (C) ref3-3 seedlings. Bar $=3 \mathrm{~mm}$.

Determination of the percentages of apoplastic water and air in the wild-type seedlings treated with PIP showed an increase in the percentage of apoplastic water and a decrease of the percentage of apoplastic air in comparison with the control but the percentage of apoplastic water was still a bit lower in the less-lignin mutant (Figure 8). Because the inhibition of $\mathrm{C} 4 \mathrm{H}$ by PIP can have a significant effect on lignin synthesis, subsequent analyses were conducted to determine the changes in total lignin in response to this inhibitor (Table 2). The results indicated that the total lignin in the seedlings treated by PIP significantly differed from those of the controls and that no significant difference was found with the less-lignin mutants (ref3-1 and ref3-3). In order to support the findings of the lignin content determinations, the enzymatic activity of $\mathrm{C} 4 \mathrm{H}$ was measured. The Arabidopsis wildtype seedlings cultured on PIP treatment showed a significant decrease in $\mathrm{C} 4 \mathrm{H}$ activity compared to the control while no significant differences were found with the less-lignin mutant seedlings (Figure 9). This is in agreement with [10] who noted that the ref3 mutation affected protein stability and enzyme function.

Moreover, there were no significant morphological differences between seedlings treated by PIP or from the less-lignin mutant and those of $0.4 \%(w / v)$ gelrite (data not shown). The results on $\mathrm{C} 4 \mathrm{H}$ activity were totally in accordance with the results on total lignin content (Table 2). To further link HH to lignin biosynthesis and in particular to $\mathrm{C} 4 \mathrm{H}$ we looked at the expression profile of the lignin biosynthesis-related $\mathrm{C} 4 \mathrm{H}$ gene in the wild-type seedlings (Ler and Col-0) and in less-lignin mutant seedlings (ref3-1 and ref3-3) (Figure 10). The expression pattern of the C4Hgene was positively correlated with the total lignin content (rho $=0.821$ ) and the expression level of the $\mathrm{C} 4 \mathrm{H}$ gene in the less-lignin mutant was found lower compared to the wild-type. 


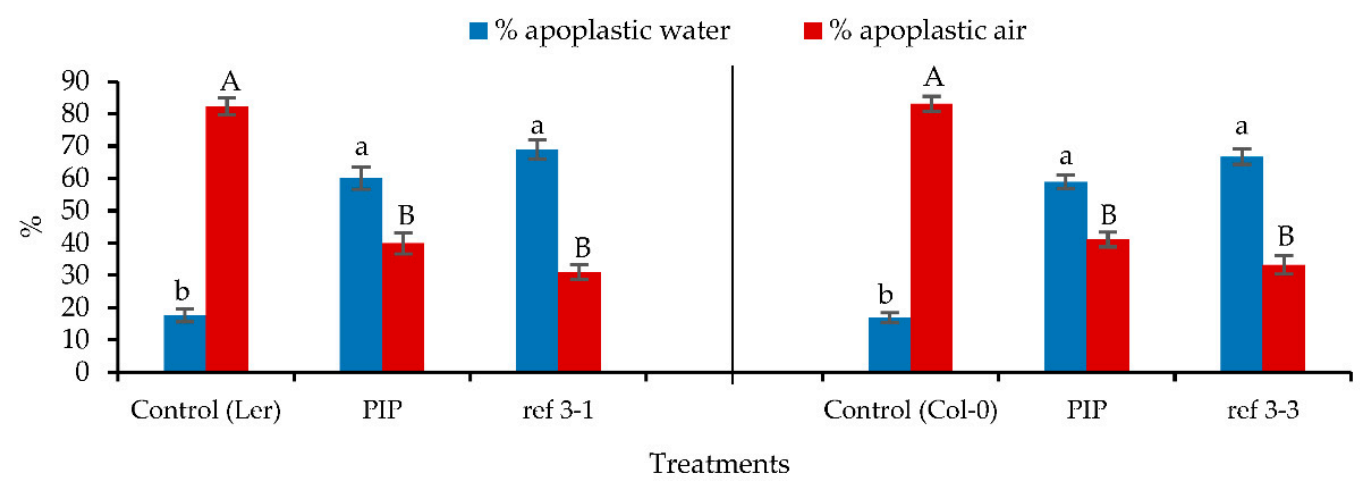

Figure 8. The percentages of apoplastic water and air related to the total volume of the apoplast in Arabidopsis thaliana Ler, Col-0, ref3-1, and ref3-3 seedlings on $0.7 \%(w / v)$ Micro-agar after 14 days of culture. Different letters indicate significant differences between means at $\alpha=0.05$ level.

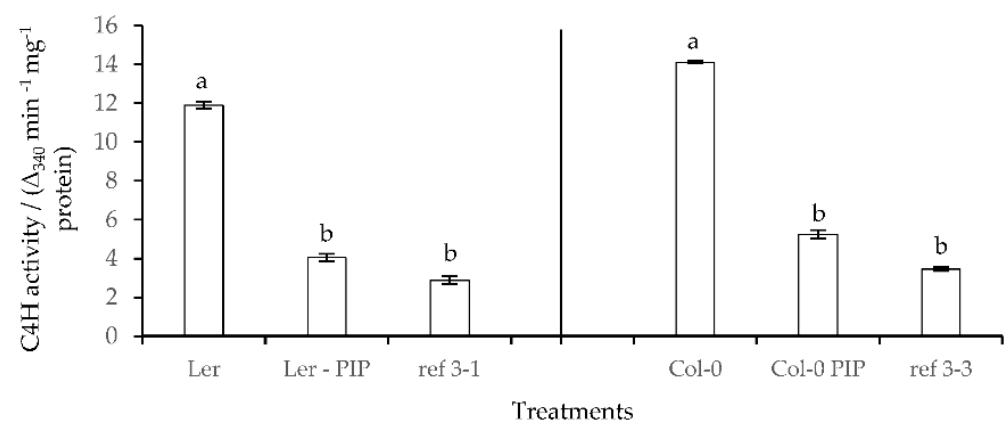

Figure 9. $\mathrm{C} 4 \mathrm{H}$ activity of Arabidopsis thaliana Ler, Col-0, ref3-1, and ref3-3 seedlings on $0.7 \%(w / v)$ Micro-agar (control) after 14 days of culture. Different letters indicate significant differences between means at $\alpha=0.05$ level.

Table 2. Total lignin of Arabidopsis thaliana wild-type, less-lignin-mutant, and wild-type + PIP on Mico-agar medium.

\begin{tabular}{|c|c|}
\hline Line & Lignin $\left(\mathrm{A}_{280} \mathrm{mg} \mathrm{g}^{-1}\right.$ Cell Walls) \\
\hline Ler $0.7 \%$ Micro-agar (control) & $0.0196 \pm 0.0004^{\mathrm{a}}$ \\
\hline Ler Micro-agar $+100 \mu \mathrm{M}$ PIP & $0.0090 \pm 0.0007^{b}$ \\
\hline ref3-1 Micro-agar & $0.0080 \pm 0.0003^{b}$ \\
\hline Col-0 0.7\% Micro-agar (control) & $0.0216 \pm 0.0005^{\mathrm{a}}$ \\
\hline Col-0 Micro-agar $+100 \mu \mathrm{M}$ PIP & $0.0099 \pm 0.0008^{b}$ \\
\hline ref3-3 Micro-agar & $0.0087 \pm 0.0004^{b}$ \\
\hline
\end{tabular}

The means of 9 leaves \pm SE are presented; letters indicate significant differences between means at $\alpha=0.05$ level.

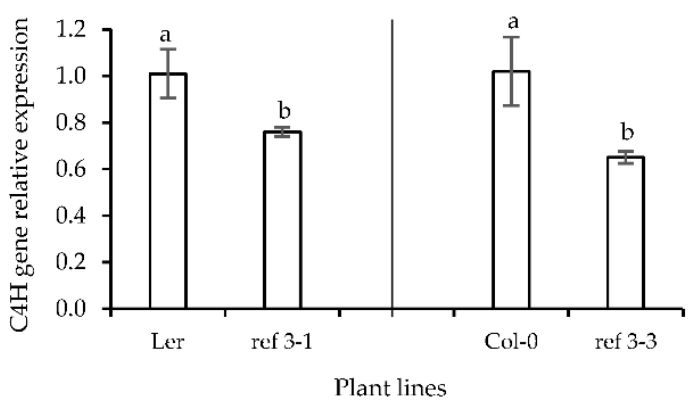

Figure 10. $\mathrm{C} 4 \mathrm{H}$ gene expression profile of Arabidopsis thaliana wild-type (set at 1.0) and less-lignin mutant seedlings on $0.7 \%(w / v)$ Micro-agar. Different letters indicate significant differences between means at $\alpha=0.05$ level. 


\subsection{PAL Activity in Normal and Hyperhydric Arabidopsis thaliana Col-0 Seedlings}

PAL is the first enzyme involved in the core and entry pathway of the phenylpropanoid pathway and in the biosynthesis of lignin. In order to confirm the role of lignin in $\mathrm{HH}, \mathrm{PAL}$ activity of normal and hyperhydric Arabidopsis thaliana Col-0 seedlings were measured. PAL activity in hyperhydric leaves was significantly decreased compared to normal leaves (Figure 11) as was the lignin content (Table 1). This confirmed the importance of lignin and lignin biosynthesis in the development of $\mathrm{HH}$.

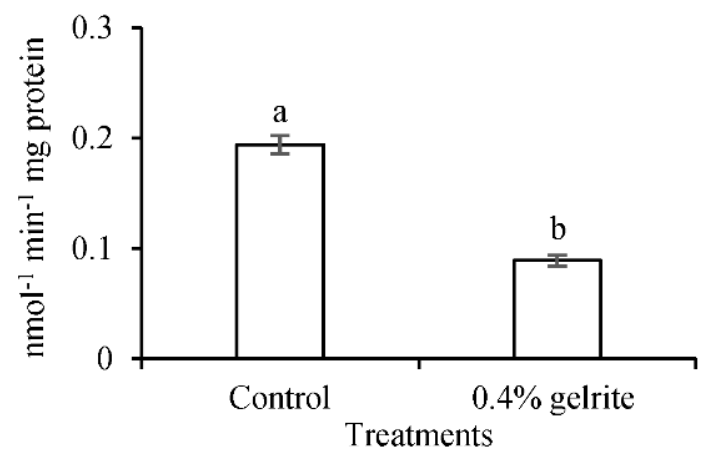

Figure 11. PAL activity of 14 days old Arabidopsis thaliana Col-0 leaves on $0.7 \%(w / v)$ Micro-agar (control) and $0.4 \%(w / v)$ gelrite medium. a and b letters indicate significant differences between means at $\alpha=0.05$ level.

\subsection{Leaf Anatomy}

To investigate whether any visible cell wall defects could be observed in ref3-3 seedlings, we looked at the ultrastructure of leaves of the wild-type control with and without PIP treatment and of the mutant ref3-3 by light microscopy. The palisade cells of wild-type leaves were well-organized (Figure 11); however, the palisade cells in the leaves treated with PIP and the mutant were arranged parallel to the epidermal cells with an altered cell shape (Figure 12B,C). These image results were consistent with the observed curling of PIP treated leaves and mutant leaves. Moreover, wild-type vascular bundles were collateral with lignified vessels (Figure 12D, the arrows point towards the lignified compounds (bluish). On the other hand, differentiation of vascular tissue and celular organization pattern of mutant leaves was observed (Figure 12E) which showed shrunken and poor lignification and hardly any xylem consistent with the low levels of lignin deposited in these leaves (Table 2). The same leaf pattern was applied PIP treated leaves.
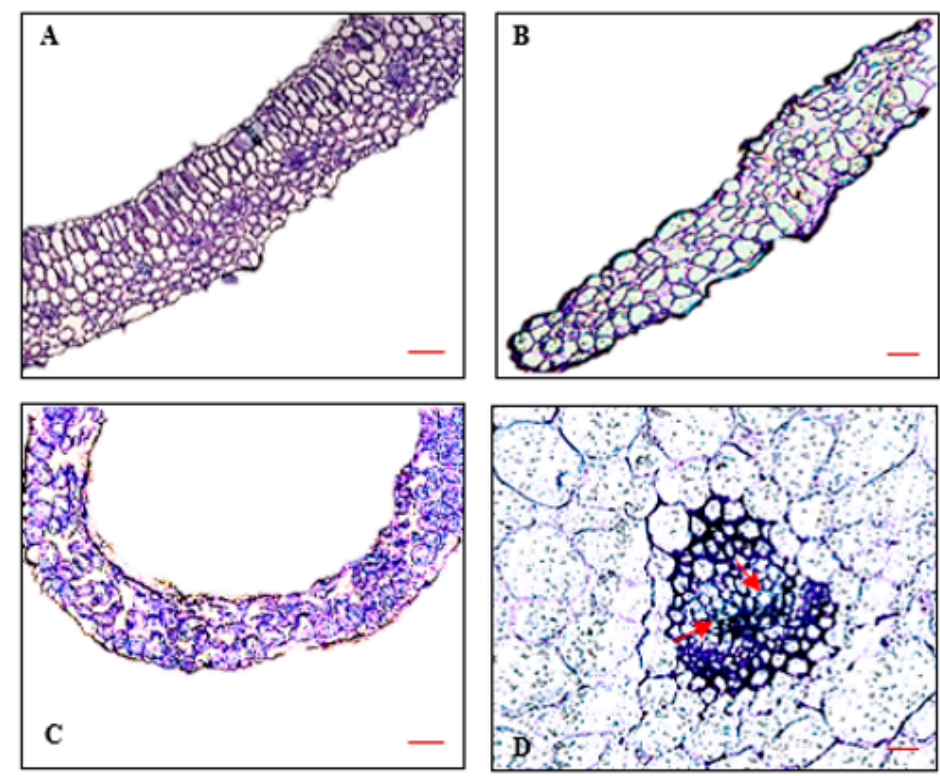

Figure 12. Cont. 


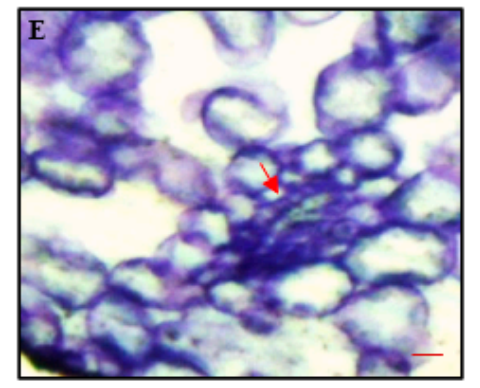

Figure 12. Toluidine blue-stained sections of 14 days old Arabidopsis leaves. (A) Wild-type (Col-0) on control media, (B) Wild-type (Col-0) treated with PIP on Micro-agar, (C) ref3-3 mutant on Micro-agar, (D) vascular bundle and cellular organization pattern of normal Wild-type (Col-0) on control media

(E) hyperhydric ref3-3 mutant leaves on Micro-agar. Bar $=50 \mu \mathrm{m}(\mathbf{A}-\mathbf{C}), 100 \mu \mathrm{m}(\mathbf{D}, \mathbf{E})$.

\section{Discussion}

The plant shikimate pathway is the entry to the biosynthesis of phenylpropanoids. Anterola and Lewis [37] mentioned that lignin levels are regulated by enzymes together with their corresponding genes $\mathrm{C} 4 \mathrm{H}$, resulting in an increase in $\mathrm{H}$ lignin. A decisive step in this important phenylpropanoid biosynthesis pathway is presented by $\mathrm{C} 4 \mathrm{H}$, the second enzymatic step, crucial in lignin synthesis. By blocking this step, the ability of plants to produce lignin is impaired. In addition to a role in support, lignin plays a crucial part in conducting water in the plant due to its polysaccharide components that are hydrophobic compared to other polysaccharide components which are highly hydrophilic. The crosslinking of polysaccharides by lignin is an obstacle for water absorption into the cell wall. As reported by [7], hyperhydric plants have a deficiency in both cellulose and lignin synthesis and [14] identified a single C4H mis-sense mutation in At2g30490 (ref3) that severely affected growth and lignin development in leaves of Arabidopsis. Combining these two observations led us to investigate the role of lignin in the development of $\mathrm{HH}$.

To confirm a supposed entry of exogenously applied $p$-coumaric acid into the phenylpropanoid pathway, experiments were performed by growing the Arabidopsis wild-type (Ler and Col-0) seedlings with different concentration of $p$-coumaric acid. We found that exogenously applied $p$-coumaric acid $(100 \mu \mathrm{M})$ in both wild-type genotypes was optimal and showed a reduction in $\mathrm{HH}$ on $0.4 \%(w / v)$ gelrite medium. Exogenous supply of p-coumaric acid $(100 \mu \mathrm{M})$ to less-lignin mutants (ref3-1 and ref3-3) also resulted in similar effects which a decrease in development of hyperhydric symptoms. Higher concentrations of $p$-coumaric acid might prove to be better in these mutants but this was not tested. Besides, the addition of $p$-coumaric acid to $0.4 \%(w / v)$ gelrite also showed a pronounced decrease in root growth when compared to $0.4 \%(w / v)$ gelrite alone. The inhibitory effect of $p$-coumaric acid treatments on root growth might be related to the increase in lignification, leading to a decrease in root pressure and consequently reducing $\mathrm{HH}$.

Lignification, the metabolic process of sealing a plant cell wall by lignin deposition, occurs during the course of normal tissue development and it is an important step during root growth. The most important finding of the current study was that $p$-coumaric acid not only significantly reduced the root growth of the seedlings on $0.4 \%(w / v)$ gelrite medium but also increased total lignin (Table 1). This finding is of particular interest because the reduction in root growth has been considered one of the first effects of $p$-coumaric acid associated with premature lignification of the cell walls $[16,32]$. These results were also obtained in parallel in many plant species as documented by $[16,33,36,38]$. These reports and the recent observations strengthen the notion of a possible influx of $p$-coumaric and ferulic acid into the phenylpropanoid pathway, followed by increases in total lignin that strengthen the cell wall and reduce root growth. Additionally, according to [37] the studies of lignin deposition in tissue cultures have for the most part been oriented towards elucidating the biochemistry of lignin synthesis. Besides, [39,40] showed a similar action of eugenol, cinnamic acid, and its derivatives on the lignification of isolated plant organs. 
It is known that Arabidopsis ref3 mutants, characterized by an allelic series bearing missense mutations in the gene encoding $\mathrm{C} 4 \mathrm{H}$, failed to accumulate wild-type levels of sinapoylmalate [14,41]. The authors demonstrated that the genetic changes in ref3 mutants had led to altered stability and substrate binding capacity of the mutant $\mathrm{C} 4 \mathrm{H}$ enzymes. In our studies, significant decreases in total lignin in the ref3 seedlings on Micro-agar medium were observed and significant increases in total lignin after the addition of $p$-coumaric acid to the media. These results suggested that exogenously applied $p$-coumaric acid can be channelled into the phenylpropanoid pathway at this metabolic point. Previous reports provided evidence supporting that ref3 seeds had reduced levels of condensed tannins and were low in lignin deposition [14].

To confirm the role of lignin and the $\mathrm{C} 4 \mathrm{H}$-based phenylpropanoid pathway in $\mathrm{HH}$, additional experiments were conducted to mimic the $\mathrm{C} 4 \mathrm{H}$ mutants (ref3) by culturing control seedlings with PIP (a specific inhibitor of $\mathrm{C} 4 \mathrm{H}$ ) on Micro-agar medium. The results showed that the seedlings developed HH symptoms accompanied by significant increases in the percentage of apoplastic water and concurrent decreases in the percentage of apoplastic air. In fact, the seedlings after PIP treatment also demonstrated a reduction in total lignin when compared to the control treatment without PIP. For both apoplastic properties and lignin, it was observed that the seedlings after PIP treatment were not significantly different from the ref3 mutants. Because PIP inhibits the $\mathrm{C} 4 \mathrm{H}$ reaction, thereby blocking the phenylpropanoid pathway, it thus affected the lignin biosynthesis and caused $\mathrm{HH}$. Moreover, transverse sections of the leaves in Figure 12 showed that the $\mathrm{C} 4 \mathrm{H}$ modifications caused similar cellular disorganization and cell wall defects in the seedlings treated by PIP and of the less-lignin mutant. Based on our results, we hypothesize that these cellular deficiencies with large intercellular spaces (ICs) and little lignin deposition were responsible for rendering the apoplast more hydrophilic and together with the effect of higher root pressure and high relative humidity in the headspace eventually caused $\mathrm{HH}$. Reduction of root by adding $p$-coumaric acid, decreased the root pressure thus less water absorbed from the gelling medium thereby reduced the symptoms of $\mathrm{HH}$.

The present study demonstrated that the changes in $\mathrm{C} 4 \mathrm{H}$ activity affected total lignin. $\mathrm{C} 4 \mathrm{H}$ is the first $\mathrm{P} 450$-dependent monooxygenase of the phenylpropanoid pathway, and it is widely expressed in various tissues, particularly in roots and cells undergoing lignification [33]. In fact, [42] demonstrated a correlation between $\mathrm{C} 4 \mathrm{H}$ activity and the deposition of lignin in phloem and xylem fiber cells of Zinnia elegans. Interestingly on top of the changed $\mathrm{C} 4 \mathrm{H}$ enzyme activity due to a single amino acid substitution, the $\mathrm{C} 4 \mathrm{H}$ gene expression in the ref single base pair mutants also was reduced compared to the wildtype. This complied to the findings by [43] who found that the transcript level of RPS4 in the chlorophyll-deficient mutant $(c d m)$ of Chinese cabbage, carrying a single base-pair point mutation leading to a single amino acid substitution, was lower than than in the wild-type (Fukuda 50 FT). Together, less transcription and translation, so less enzyme, combined with the reduced activity of the enzyme caused by the mutation-induced amino acid substitutions will have led to a lower lignin.

Besides, our studies demonstrated that the overall anatomical features of leaves of the PIP treated seedlings and of the mutants were significantly altered compared to the wild-type control. The normal leaves (control) contained vascular bundles with lignified xylem elements, whereas hyperhydric ones were poorly lignified on PIP and ref3-3 mutant. The normal leaves exhibited well-defined palisade formed by single cell layer and layers of spongy mesophyll cells with reduced intercelullar spaces, meanwhile the hyperhydric leaves appeared to have an unorganized spongy mesophyll with large intercellular spaces, the cells were dispered and not as elongated as in the normal leaves. This explained an increase on the percentage of apoplastic water in the apoplast. These findings concur with those of [44] who found cell wall defects occurred on knockout AtCESA2 gene in Arabidopsis Ler and the leaves curling much more than the wild-type. Similarly documented by $[3,4]$ the leaves of hyperhydric shoots were characterized by the lack of clear differentiation between the palisade and the spongy parenchyma. 
Moreover, PAL is the main enzyme in the initiation of the lignin biosynthesis pathway. A reduction of cell wall lignification may alter the mechanical properties of the cell wall [45]. These changes could lead to a reduction in cell turgor pressure and to a change in water potential, which would further result in the increased water uptake and finally in the occurrence of $\mathrm{HH}$. Our results clearly demonstrated a reversed relationship between PAL activity and the degree of lignification in Arabidopsis, confirming the positive effect of lignin on $\mathrm{HH}$. The results were in line $[46,47]$ who also found lower activity of PAL in HH carnation species. The simultaneous development of $\mathrm{HH}$ in these experiments suggested that lignin plays an important role in the development of $\mathrm{HH}$.

\section{Conclusions}

The focus of the present work was to investigate the role of lignin in HH. Physiological and anatomical studies, combined with biochemical assays, suggest that lignin plays a pivotal role in the development of $\mathrm{HH}$ during in vitro propagation. Our results showed that the possible influx of exogenously applied $p$-coumaric acid, a precursor for lignin, to Gelrite solidified medium, led to increases in total lignin that strengthen the cell wall and reduce root growth. Exogenously applied $p$-coumaric acid reduced HH symptoms, decreased the percentage of the apoplastic water volume, increased the percentage of apoplastic air volume, inhibited root growth and increased the total lignin content in Arabidopsis thaliana wild-types and less-lignin mutants plantlets. Further confirmation of the role of lignin and the phenylpropanoid pathway in HH development comes from the results of Arabidopsis thaliana less-lignin mutants ref3-1 and ref3-3. On top of this, exogenous application of PIP, an inhibitor of the $\mathrm{C} 4 \mathrm{H}$ enzyme, to Arabidopsis wild-type (Col-0) seedlings on Micro-agar medium raised the percentage of apoplastic water and decreased total lignin content. Progress was made in the study of the role of lignin in $\mathrm{HH}$, but more input is required to see how this knowledge can be put to use in preventing HH. Combining $p$-coumaric acid with other beneficial compounds, which could act synergistically in preventing $\mathrm{HH}$, are the next step to be taken.

\section{Materials and Methods}

\subsection{Plant Materials}

Arabidopsis thaliana wild-types, Col-0 and Ler, and the less-lignin mutants, ref3-1 (Ler genetic background) and ref 3-3 (Col-0 genetic background), seeds were sterilized with $70 \%$ $(v / v)$ ethanol for $1 \mathrm{~min}$ and $2 \%(w / v)$ sodium hypochlorite for $15 \mathrm{~min}$ and subsequently rinsed three times for $10 \mathrm{~min}$ with sterilized distilled water. Then, the seeds were sown in a Petri dish with half-strength Murashige and Skoog (MS) medium including vitamins [48] supplemented with $1.5 \%(w / v)$ sucrose and solidified with $0.7 \%(w / v)$ Micro-agar, $\mathrm{pH} 5.8$. To synchronize germination, the seeds were stratified in the dark for 3 days at $4{ }^{\circ} \mathrm{C}$ and after that transferred to a climate room for germination. Growing conditions were at $21^{\circ} \mathrm{C}$ with $16 \mathrm{~h} \mathrm{light} / 8 \mathrm{~h}$ dark $\left(30 \mu \mathrm{mol} \mathrm{m}{ }^{-2} \mathrm{~s}^{-1}\right.$, Philips TL33). The measurements on apoplastic water, apoplastic air, total lignin, $\mathrm{C} 4 \mathrm{H}$ oxidase activity and gene expression analysis were evaluated on 14-days-old seedlings.

\subsection{Experimental Setup}

To investigate the effect of adding $p$-coumaric acid, 7-day-old Arabidopsis thaliana wildtype (Col-0) seedlings were transferred to half-strength MS medium including vitamins supplemented with $1.5 \%(w / v)$ sucrose supplemented with $p$-coumaric acid at concentrations of $0,10,100$, and $500 \mu \mathrm{M}$; the media were solidified with $0.7 \%(w / v)$ Micro-agar or $0.4 \%(w / v)$ gelrite. The optimal concentration of $p$-coumaric acid determined from the experiment above was used in the subsequent treatments of the Arabidopsis thaliana less-lignin $\mathrm{C} 4 \mathrm{H}$ (At2g30490) ethyl methanesulfonate-induced ref3 mutants, ref3-1 from Ler background and ref3-3 from Col-0 background. To confirm the role of lignin and $\mathrm{C} 4 \mathrm{H}$ activity in $\mathrm{HH}$, an experiment with $100 \mu \mathrm{M}$ PIP in the nutrient medium solidified with $0.7 \%(w / v)$ Micro-agar was conducted on Arabidopsis thaliana seedlings of Ler, Col-0 
and the less-lignin mutants, ref3-1 and ref3. Half-strength MS medium including vitamins supplemented with $1.5 \%(w / v)$ sucrose solidified with $0.7 \%(w / v)$ Micro-agar acted as control.

\subsection{Extraction of Cell Walls and Total Lignin Determination}

Cell walls were extracted according to [49] with minor modifications. Arabidopsis leaves were freeze dried overnight and were ground using mortar and pestle. Each treatment sample consisted of $100 \mathrm{mg}$ powder. The powder was incubated in $10 \mathrm{~mL}$ of methanol (MeOH) for $15 \mathrm{~min}$ at $20^{\circ} \mathrm{C}$ using a thermomixer (Eppendorf ${ }^{\circledR}$ Thermomixer Compact, 5384000020, USA). The suspension was centrifuged at $2750 \mathrm{rpm}$ for $5 \mathrm{~min}$, then the supernatant was discarded. Next, $10 \mathrm{~mL}$ of fresh $\mathrm{MeOH}$ was added to the pellet and incubated for $30 \mathrm{~min}$ at $60{ }^{\circ} \mathrm{C}$, followed by centrifugation at $2750 \mathrm{rpm}$ for $5 \mathrm{~min}$, and again the supernatant was removed. The extraction with $\mathrm{MeOH}\left(30 \mathrm{~min}\right.$ at $\left.60^{\circ} \mathrm{C}\right)$ was repeated and centrifuged until the supernatant was colourless. The pellet was resuspended in $10 \mathrm{~mL}$ of mili-Q water and washed three times. The last pellet was resuspended in $10 \mathrm{~mL}$ of $0.5 \mathrm{M}$ phosphate buffer ( $\mathrm{pH} 7.0)$ containing $5 \%(v / v)$ ethanol $(\mathrm{EtOH})$ and $0.02 \%(w / v)$ protease (Pronase E, Sigma Aldrich). This suspension was incubated for $18 \mathrm{~h}$ at $37^{\circ} \mathrm{C}$ and centrifuged at $2750 \mathrm{rpm}$ for $5 \mathrm{~min}$, after which resuspension of the pellet in $10 \mathrm{~mL}$ of solvent and centrifugation under the same conditions was performed consecutively: $3 \times$ with distilled water as solvent, $3 \times$ with $95 \%(v / v) \mathrm{EtOH}$, and $2 \times$ with absolute $\mathrm{EtOH}$. EtOH residue was removed using vacuum and the final weight of the pellet (cell wall material) was recorded. The total lignin was determined using the acetyl bromide method [50]. Absorption was measured at $280 \mathrm{~nm}$ wavelength and optical density inserted in the following $\mathrm{ABL}$ equation: $\mathrm{X}=(\mathrm{Y}-0.0009) / 23.077$, where $\mathrm{X}$ is concentration of lignin $(\mathrm{mg} / \mathrm{mL}), Y$ is the optical density reading of unknown sample, 0.0009 is the mean intercept value, and 23.077 is the mean extinction coefficient obtained from this work.

\subsection{Evaluation of Apoplastic Water and Air Volumes in Leaves}

The volume of apoplastic water was measured by mild centrifugation [51]. The leaves were excised and weighed, and put in the microfilter centrifuge tube. Leaves were centrifuged at $3000 \times g$ for $20 \mathrm{~min}$ at $4{ }^{\circ} \mathrm{C}$. Immediately after centrifugation, the leaves were reweighed. The apoplastic water volume (Vwater) in $\mu \mathrm{L} \mathrm{g}^{-1} \mathrm{FW}$ was calculated using the formula [52]: Vwater $=\left[(\mathrm{FW}-\mathrm{Wac}) \times \rho \mathrm{H}_{2} \mathrm{O}\right] / \mathrm{FW}$. Where $\mathrm{FW}=$ fresh weight of leaves in $\mathrm{mg}$, Wac $=$ weight of leaves after centrifugation and $\rho \mathrm{H}_{2} \mathrm{O}=$ water density (the water density was taken as equal to $1 \mathrm{~g} \mathrm{~mL}^{-1}$ ).

The volume of apoplastic air in leaves was measured using a pycnometer with a stopper following the methods of [52]. The leaves were excised, weighed, and then placed into the pycnometer. The pycnometer was then filled with distilled water and the stopper was put in place. The weight of the full pycnometer including leaves, was measured and then the stopper was removed and replaced with a gauze. The pycnometer was placed in a vacuum for $5 \mathrm{~min}$ to remove air out of the leaves and this was repeated until all air was removed from the apoplast and the leaves had sunk to the bottom. After that the gauze was removed, the pycnometer refilled with water until it was full without any air-bubbles, it was subsequently dried, and reweighed together with the stopper. The apoplastic air volume (Vair) in $\mu \mathrm{L} \mathrm{g}^{-1} \mathrm{FW}$ was calculated using the following formula [52]: Vair $=\left[(\mathrm{Wbv}-\mathrm{Wav}) \times \rho \mathrm{H}_{2} \mathrm{O}\right] / \mathrm{FW}$. Where $\mathrm{Wbv}=$ weight in $\mathrm{mg}$ of the pycnometer including leaves and water before vacuum infiltration, Wav = weight of the pycnometer including leaves and water after vacuum infiltration, $\mathrm{FW}=$ fresh weight of leaves, and $\rho \mathrm{H}_{2} \mathrm{O}=$ water density.

The mean percentages of apoplastic water and apoplastic air related to the total apoplast volume were calculated using the following formula \%tmvw or \%tmva $=100 \times \operatorname{tmvw}$ or tmva/Tmap. Here, tmvw was the mean volume of apoplastic water, tmva was the mean volume of apoplastic air, Tmap was the mean total volume of the apoplast, so water + air. 


\subsection{Root Growth Determination}

Root growth was recorded by taking a picture from the bottom of petri dishes of seedlings after 14 days of culture on $0.7 \%$ Micro-agar (as Control), $0.4 \%$ gelrite, and $100 \mu \mathrm{M}$ $p$-coumaric acid $0.4 \%$ gelrite medium. The pictures were used for a visual evaluation and estimation of growth of the roots.

\subsection{Enzyme Extraction and C4H Activity Assay}

$\mathrm{C} 4 \mathrm{H}$ was extracted using a modified version of the method of [53]. Fifty milligrams of leaves (fresh weight) were ground to a fine powder in liquid nitrogen using a mortar and pestle. The powder obtained was extracted using a $0.5 \mathrm{~mL}$ solution of $0.05 \mathrm{~mol} / \mathrm{L}$ Tris- $\mathrm{HCl}$ buffer (pH 8.9) containing $15 \mathrm{mmol} / \mathrm{L} \beta$-mercaptoethanol, $4 \mathrm{mmol} / \mathrm{L} \mathrm{MgCl}$, $2.5 \mathrm{mmol} / \mathrm{L}$ ascorbic acid, $10 \mathrm{mmol} / \mathrm{L}$ leupeptin, $1 \mathrm{mmol} / \mathrm{L}$ phenylmethylsulfonyl fluoride, and $0.15 \%(w / v)$ polyvinylpyrrolidone and $10 \%(v / v)$ glycerine, and the homogenate was centrifuged at $10,000 \times \mathrm{g}$ for $15 \mathrm{~min}$ at $4{ }^{\circ} \mathrm{C}$. The supernatant was collected and then stored at $4{ }^{\circ} \mathrm{C}$ for the measurement of $\mathrm{C} 4 \mathrm{H}$ activity. For this, the reaction mixtures contained $1.1 \mathrm{~mL}$ of $0.05 \mathrm{~mol} / \mathrm{L}$ Tris- $\mathrm{HCl}$ buffer (pH 8.9), consisting of $2 \mu \mathrm{mol} / \mathrm{L}$ trans-cinnamic acid, $2 \mu \mathrm{mol} / \mathrm{L} \beta$-nicotinamide adenine di-nucleotide phosphate disodium salt, and $5 \mu \mathrm{mol} / \mathrm{L}$ D-glucose 6-phosphate sodium salt hydrate. Then, $0.15 \mathrm{~mL}$ of the extract was added to the mixture to initiate the reaction. The mixture was agitated for $30 \mathrm{~min}$ at $25^{\circ} \mathrm{C}$ using a thermomixer (Eppendorf ${ }^{\circledR}$ Thermomixer Compact, 5384000020, New York, NY, USA) and the reaction was stopped by adding $50 \mu \mathrm{L}$ of $6 \mathrm{M} \mathrm{HCl}$. The activity of $\mathrm{C} 4 \mathrm{H}$ was assayed by measuring the increase in absorbance at $340 \mathrm{~nm}$ using UV- Spectrophotometer. One unit of $\mathrm{C} 4 \mathrm{H}$ activity was defined as the amount of enzyme catalyzing an increase in absorbance of 0.01 per minute per miligram fresh weight (total protein).

\subsection{Quantitative Real-Time PCR ( $q P C R$ )}

Total RNA was isolated from the leaves (100 mg fresh weight) using an RNeasy ${ }^{\circledR}$ kit (Qiagen, Hilden, Germany) according to the manufacturer's protocols. The quantity and quality of RNA were determined using NanoDrop $1000^{\mathrm{TM}}$ and gel electrophoresis. The extracted RNA served as template for the synthesis of single-stranded cDNA. cDNA was synthesised using $1 \mu \mathrm{g}$ of RNA samples with an iScript cDNA Synthesis Kit (Bio-Rad Laboratories, Inc., Hercules, CA, USA). Quantitative Real-Time PCR was performed using the SYBR GREEN super mix (Bio-Rad Laboratories, Inc., Hercules, CA, USA). All qRT-PCR assays were performed as follows: preheating $95^{\circ} \mathrm{C}$ for $3 \mathrm{~min}, 40$ cycles of $95^{\circ} \mathrm{C}$ for $15 \mathrm{~s}$ and $55{ }^{\circ} \mathrm{C}$ for $30 \mathrm{~s}$. At the end of the PCR, the temperature was increased gradually from $55^{\circ} \mathrm{C}$ to $95^{\circ} \mathrm{C}$ to generate the melting curve. The expression of gene $\mathrm{C} 4 \mathrm{H}$ : At2g30490 was measured. The expression level of the gene of interest was normalized to the expression level of the reference gene CYCLIN-DEPENDENT KINASE A1 (CDKA: At3g48750). The relative gene expression was determined based on the $2^{-\delta \mathrm{Ct}}$ calculation method [54]. The primer pairs were retrieved from literature [55]. Primer pair $\mathrm{C} 4 \mathrm{H}$ : $5^{\prime}$-CACCGGGAAAGGTCAAGATA- $3^{\prime}$ and $5^{\prime}$-CCCAACCTTCACGATTCTGT- ${ }^{\prime}$; CDKA: $5^{\prime}$-ATTGCGTATTGCCACTCTCATAGG-3' ${ }^{\prime}$ and $5^{\prime}$-TCCTGACAGGGATACCGAATGC-3'.

\subsection{Determination of Phenylalanine Ammonia-Lyase (PAL) Activity}

PAL activity was determined measuring trans-cinnamic acid (CA) content produced as previously described by [56] with slight modifications. Leaf tissue samples weighing $0.3 \mathrm{~g}$ derived from $0.7 \%(w / v)$ Micro-agar (Control) and $0.4 \%(w / v)$ gelrite seedlings were homogenized in $0.1 \mathrm{M}$ sodium borate $(\mathrm{pH} 8.8)$ and centrifuged for $10 \mathrm{~min}$ at $4{ }^{\circ} \mathrm{C}$ at $12,000 \times g$. The supernatant was saved and used for determining protein content using the Bradford procedure. Five hundred microliters of buffer and three hundred and fifty microliters of homogenates as a reaction mixture were pre-incubated at $37^{\circ} \mathrm{C}$ for $5 \mathrm{~min}$. The reaction was started by addition of $300 \mu \mathrm{L} 50 \mathrm{mM}$ L-phenylalanine (Sigma-Aldrich, Taufkirchen, Germany). After $3 \mathrm{~h}$ of incubation at $37^{\circ} \mathrm{C}$, the reaction was stopped by the addition of $50 \mu \mathrm{L} 5 \mathrm{~N}$ hydrochloric acid $(\mathrm{HCl})$. All samples were analyzed by spectropho- 
tometry. Parallel controls without L-phenylalanine addition were analyzed to determine plant endogenous trans-cinnamic acid (CA) content. The amount of CA was monitored at $290 \mathrm{~nm}$ absorbance.

\subsection{Microscopy}

For lignin deposition, Arabidopsis thaliana wild-type and mutant (ref) seedlings were fixed in 5\% $(v / v)$ glutaraldehyde solution in $0.1 \mathrm{M}$ phosphate-buffer $(\mathrm{pH} 7.2)$ for $2 \mathrm{~h}$ at $4{ }^{\circ} \mathrm{C}$. Subsequently, they were washed four times for $15 \mathrm{~min}$ in $0.1 \mathrm{M}$ phosphate-buffer ( $\mathrm{pH}$ 7.2), then twice for $15 \mathrm{~min}$ in water. The samples were then dehydrated in a gradient series of ethanol and subsequently embedded in Technovit 7100 (Heraeus-Kulzer Technik, Germany). Infiltration in Technovit was performed according to the manufacturer's instructions. The samples were then sectioned transversely ( $5 \mu \mathrm{m}$-thick) with a rotary microtome, mounted onto a glass slide, dried, and stained with $0.05 \%(w / v)$ toluidine blue $\mathrm{O}$ in phosphate-buffer at $\mathrm{pH}$ 6.8. The pictures were made under an Axiophot light microscope (AxioVision software release 4.8.2 (Zeiss, Jena, Germany).

\subsection{Statistical Data Analysis}

For all of the treatments and measurements three repeats of each with 15 plants, were used except for anatomical analysis. The means $\pm \mathrm{SE}$ are given in the graphs. Data were subjected to one-way analysis of variance (ANOVA) and means were compared using Duncan's multiple range test at $p \leq 0.05$. All experiments were carried out at least twice.

Author Contributions: N.K. conceived the idea, designed and performed the experiments, analyzed data, wrote and edited the manuscript. R.G.F.V. and F.A.K. revised the manuscript. All authors have read and agreed to the published version of the manuscript.

Funding: This research was funded by Ministry of Higher Education Malaysia and Universiti Putra Malaysia, grant number 9001103 and in part by the Dutch Ministry of Economic Affairs, TKI-TU grant number KV1310-067.

Institutional Review Board Statement: Not applicable.

Informed Consent Statement: Not applicable.

Data Availability Statement: The data presented in this study are available in this article.

Acknowledgments: The authors would like to thank G.J.M. De Klerk for his valuable inputs and expertise that greatly assisted during the initial phase of the research.

Conflicts of Interest: The authors declare no conflict of interest.

\section{References}

1. Ziv, M. Quality of micropropagated plants-Vitrification. In Vitro Cell. Dev. Biol. Plant 1991, 27, 64-69. [CrossRef]

2. Franck, T.; Crèvecoeur, M.; Wuest, J.; Greppin, H.; Gaspar, T. Cytological Comparison of Leaves and Stems of Prunus avium L. Shoots Cultured on a Solid Medium with Agar or Gelrite. Biotech. Histochem. 1998, 73, 32-43. [CrossRef]

3. Olmos, E.; Hellín, E. Ultrastructural differences of hyperhydric and normal leaves from regenerated carnation plants. Sci. Hortic. 1998, 75, 91-101. [CrossRef]

4. Picoli, E.A.; Otoni, W.; Figueira, M.L.; Carolino, S.M.; Almeida, R.S.; Silva, E.A.; Carvalho, C.R.; Fontes, E. Hyperhydricity in in vitro eggplant regenerated plants: Structural characteristics and involvement of BiP (Binding Protein). Plant Sci. 2001, 160, 857-868. [CrossRef]

5. Dewir, Y.; Chakrabarty, D.; Ali, M.; Hahn, E.; Paek, K.Y. Lipid peroxidation and antioxidant enzyme activities of Euphorbia millii hyperhydric shoots. Environ. Exp. Bot. 2006, 58, 93-99. [CrossRef]

6. Kevers, C.; Coumans, M.; Coumans-Gilles, M.-F.; Caspar, T. Physiological and biochemical events leading to vitrification of plants cultured in vitro. Physiol. Plant 1984, 61, 69-74. [CrossRef]

7. Kevers, C.; Prat, R.; Gaspar, T. Vitrification of carnation in vitro: Changes in cell wall mechanical properties, cellulose and lignin content. Plant Growth Regul. 1987, 5, 59-66. [CrossRef]

8. Gaspar, T.; Kevers, C.; Franck, T.; Bisbis, B.; Billard, J.P.; Huault, C.; Le Dily, F.; Petit-Paly, G.; Rideau, M.; Penel, C.; et al. Paradoxical results in the analysis of hyperhydric tissues considered as being under stress: Questions for a debate. Bulg. J. Plant Physiol. 1995, 21, 80-97. 
9. Komatsu, S.; Kobayashi, Y.; Nishizawa, K.; Nanjo, Y.; Furukawa, K. Comparative proteomics analysis of differentially expressed proteins in soybean cell wall during flooding stress. Amino Acids 2010, 39, 1435-1449. [CrossRef]

10. Barceló, A.R. Peroxidase and not lacasse is the enzyme responsible for cell wall linification in the secondary thickening of xylem vessels in Lupinus. Protoplasma 1995, 186, 41-44. [CrossRef]

11. Sarkanen, K.V.; Ludwig, C.H. Lignins, Occurrence, Formation, Structure and Reactions; Wiley-Interscience: New York, NY, USA, 1971.

12. Donaldson, L.A. Lignification and lignin topochemistry-An ultrastructural view. Phytochemistry 2001, 57, 859-876. [CrossRef]

13. Vanholme, R.; Storme, V.; Vanholme, B.; Sundin, L.; Christensen, J.H.; Goeminne, G.; Halpin, C.; Rohde, A.; Morreel, K.; Boerjan, W. A Systems Biology View of Responses to Lignin Biosynthesis Perturbations in Arabidopsis. Plant Cell 2012, 24, 3506-3529. [CrossRef] [PubMed]

14. Schilmiller, A.L.; Stout, J.; Weng, J.-K.; Humphreys, J.; Ruegger, M.O.; Chapple, C. Mutations in the cinnamate 4-hydroxylase gene impact metabolism, growth and development in Arabidopsis. Plant J. 2009, 60, 771-782. [CrossRef] [PubMed]

15. Kim, J.I.; Dolan, W.L.; Anderson, N.A.; Chapple, C. Indole Glucosinolate Biosynthesis Limits Phenylpropanoid Accumulation in Arabidopsis thaliana. Plant Cell 2015, 27, 1529-1546. [CrossRef]

16. Boerjan, W.; Ralph, J.; Baucher, M. Lignin Biosynthesis. Annu. Rev. Plant Biol. 2003, 54, 519-546. [CrossRef] [PubMed]

17. Almagro, L.; Gómez Ros, L.V.; Belchi-Navarro, S.; Bru, R.; Ros Barceló, A.; Pedreño, M.A. Class III peroxidases in plant defence reactions. J. Exp. Bot. 2009, 60, 377-390. [CrossRef]

18. Bell-Lelong, D.A.; Cusumano, J.C.; Meyer, K.; Chapple, C. Cinnamate-4-Hydroxylase Expression in Arabidopsis (Regulation in Response to Development and the Environment). Plant Physiol. 1997, 113, 729-738. [CrossRef]

19. Schmid, M.; Davison, T.S.; Henz, S.R.; Pape, U.J.; Demar, M.; Vingron, M.; Schölkopf, B.; Weigel, D.; Lohmann, J. A gene expression map of Arabidopsis thaliana development. Nat. Genet. 2005, 37, 501-506. [CrossRef] [PubMed]

20. Landry, L.G.; Chapple, C.; Last, R. Arabidopsis Mutants Lacking Phenolic Sunscreens Exhibit Enhanced Ultraviolet-B Injury and Oxidative Damage. Plant Physiol. 1995, 109, 1159-1166. [CrossRef]

21. Chapple, C.C.S.; Vogt, T.; Ellis, B.E.; Somerville, C.R. An Arabidopsis Mutant Defective in the General Phenylpropanoid Pathway. Plant Cell 1992, 4, 1413-1424. [CrossRef]

22. Ruegger, M.; Chapple, C. Mutations that reduce sinapoylmalate accumulation in Arabidopsis thaliana define loci with diverse roles in phenylpropanoid metabolism. Genetics 2001, 159, 1741-1749. [CrossRef] [PubMed]

23. Humphreys, J.M.; Chapple, C. Rewriting the lignin road-map. Curr. Opin. Plant Biol. 2002, 5, 224-229. [CrossRef]

24. Nair, R.B.; Bastress, K.L.; Ruegger, M.O.; Denault, J.W.; Chapple, C. The Arabidopsis thaliana REDUCED EPIDERMAL FLUORESCENCE1 Gene Encodes an Aldehyde Dehydrogenase Involved in Ferulic Acid and Sinapic Acid Biosynthesis. Plant Cell 2004, 16, 544-554. [CrossRef]

25. Fraser, C.M.; Chapple, C. The Phenylpropanoid Pathway in Arabidopsis. In The Arabidopsis Book; American Society of Plant Biologists: Rockville, MD, USA, 2011; pp. 1-19.

26. Taylor, N.G.; Scheible, W.-R.; Cutler, S.; Somerville, C.R.; Turner, S.R. The irregular xylem3 Locus of Arabidopsis Encodes a Cellulose Synthase Required for Secondary Cell Wall Synthesis. Plant Cell 1999, 11, 769-780. [CrossRef]

27. Jones, L.; Ennos, A.R.; Turner, S.R. Cloning and characterization of irregular xylem4 (irx4): A severely lignin-deficient mutant of Arabidopsis. Plant J. 2001, 26, 205-216. [CrossRef] [PubMed]

28. Vaughan, D.; Ord, B. Influence of phenolic acids on morphological changes in roots of Pisum sativum. J. Sci. Food Agric. 1990, 52, 289-299. [CrossRef]

29. Politycka, B. Ethylene-dependent activity of phenylalanine ammonia-lyase and lignin formation in cucumber roots exposed to phenolic allelochemicals. Acta Soc. Bot. Pol. 1999, 68, 123-127. [CrossRef]

30. Baleroni, C.R.S.; Ferrarese, M.L.L.; Braccini, A.L.; Scapim, C.A.; Ferrarese-Filho, O. Effects of ferulic and caffeic acids on canola (Brassica napus L. cv. Hyola 401) seed germination. Seed Sci. Technol. 2000, 28, 201-207.

31. Salvador, V.H.; Lima, R.; dos Santos, W.; Soares, A.R.; Böhm, P.A.F.; Marchiosi, R.; Ferrarese, M.D.L.L.; Ferrarese-Filho, O. Cinnamic Acid Increases Lignin Production and Inhibits Soybean Root Growth. PLoS ONE 2013, 8, e69105. [CrossRef]

32. dos Santos, W.; Ferrarese, M.D.L.L.; Finger, A.; Teixeira, A.C.N.; Ferrarese-Filho, O. Lignification and Related Enzymes in Glycine max Root Growth-Inhibition by Ferulic Acid. J. Chem. Ecol. 2004, 30, 1203-1212. [CrossRef]

33. Zanardo, D.I.L.; Lima, R.B.; Ferrarese, M.D.L.L.; Bubna, G.A.; Ferrarese-Filho, O. Soybean root growth inhibition and lignification induced by p-coumaric acid. Environ. Exp. Bot. 2009, 66, 25-30. [CrossRef]

34. Winkel-Shirley, B. Flavonoid biosynthesis: A colorful model for genetics, biochemistry, cell biology, and biotechnology. Plant Physiol. 2001, 126, 485-493. [CrossRef]

35. Fahrendorf, T.; Ni, W.; Shorrosh, B.S.; Dixon, R.A. Stress responses in alfalfa (Medicago sativa L.) XIX. Transcriptional activation of oxidative pentose phosphate pathway genes at the onset of the isoflavonoid phytoalexin response. Plant Mol. Biol. 1995, 28, 885-900. [CrossRef] [PubMed]

36. Teutsch, H.G.; Hasenfratz, M.P.; Lesot, A.; Stoltz, C.; Garnier, J.M.; Jeltsch, J.M.; Durst, F.; Werck-Reichhart, D. Isolation and sequence of a cDNA encoding the Jerusalem artichoke cinnamate 4-hydroxylase, a major plant cytochrome P450 involved in the general phenylpropanoid pathway. Proc. Natl. Acad. Sci. USA 1993, 90, 4102-4106. [CrossRef] [PubMed]

37. Anterola, A.M.; Lewis, N.G. Trends in lignin modification: A comprehensive analysis of the effects of genetic manipulations /mutations on lignification and vascular integrity. Phytochemistry 2002, 61, 221-294. [CrossRef] 
38. Reigosa, M.J.; Pazos-Malvido, E. Phytotoxic Effects of 21 Plant Secondary Metabolites on Arabidopsis thaliana Germination and Root Growth. J. Chem. Ecol. 2007, 33, 1456-1466. [CrossRef] [PubMed]

39. Sanchez, M.; Peña, M.J.; Revilla, G.; Zarra, I. Changes in Dehydrodiferulic Acids and Peroxidase Activity against Ferulic Acid Associated with Cell Walls during Growth of Pinus pinaster Hypocotyl. Plant Physiol. 1996, 111, 941-946. [CrossRef]

40. Janovicek, K.J.; Vyn, T.J.; Voroney, R.P.; Allen, O.B. Early corn seedling growth response to phenolic acids. Can. J. Plant Sci. 1997, 77, 391-393. [CrossRef]

41. Ng, P.L.L.; Ferrarese, M.L.L.; Huber, D.; Ravagnani, A.; Ferrarese-Filho, O. Canola (Brassica napus L.) seed germination influenced by cinnamic and benzoic acids and derivatives: Effects on peroxidase. Seed Sci. Technol. 2003, 31, 39-46. [CrossRef]

42. Lipetz, J.; Garro, A.J. Ionic Effects on Lignification and Peroxidase in Tissue Cultures. J. Cell Biol. 1965, 25, 109-116. [CrossRef]

43. Tang, X.; Wang, Y.; Zhang, Y.; Huang, S.; Liu, Z.; Fei, D.; Feng, H. A missense mutation of plastid RPS4 is associated with chlorophyll deficiency in Chinese cabbage (Brassica campestris ssp. pekinensis). BMC Plant Biol. 2018, 18, 130. [CrossRef] [PubMed]

44. Chu, Z.; Chen, H.; Zhang, Y.; Zhang, Z.; Zheng, N.; Yin, B.; Yan, H.; Zhu, L.; Zhao, X.; Yuan, M.; et al. Knockout of the AtCESA2 Gene Affects Microtubule Orientation and Causes Abnormal Cell Expansion in Arabidopsis. Plant Physiol. 2007, 143, 213-224. [CrossRef] [PubMed]

45. Lin, S.; Zhang, Z.; Lin, Y.; Liu, W.; Guo, H.; Zhang, W.; Zhang, C. Comparative study on antioxidative system in normal and vitrified shoots of Populus suaveolens in tissue culture. For. Stud. 2004, 6, 1-8. [CrossRef]

46. Saher, S.; Piqueras, A.; Hellin, E.; Olmos, E. Hyperhydricity in micropropagated carnation shoots: The role of oxidative stress. Physiol. Plant 2004, 120, 152-161. [CrossRef]

47. Kevers, C.; Gaspar, T. Vitrification on Carnation in vitro: Changes in Ethylene Production. Plant Cell Tissue Organ Cult. 1985, 4, 215-223. [CrossRef]

48. Murashige, T.; Skoog, F. A Revised Medium for Rapid Growth and Bio Assays with Tobacco Tissue Cultures. Physiol. Plant 1962, 15, 473-497. [CrossRef]

49. Estrada, B.; Bernal, M.A.; Díaz, J.; Pomar, F.; Merino, F. Fruit development in Capsicum annuum: Changes in capsaicin, lignin, free phenolics, and peroxidase patterns. J. Agric. Food Chem. 2000, 48, 6234-6239. [CrossRef]

50. Fukushima, R.S.; Kerley, M.S. Use of Lignin Extracted from Different Plant Sources as Standards in the Spectrophotometric Acetyl Bromide Lignin Method. J. Agric. Food Chem. 2011, 59, 3505-3509. [CrossRef]

51. Terry, M.E.; Bonner, B.A. An Examination of Centrifugation as a Method of Extracting an Extracellular Solution from Peas, and Its Use for the Study of Indoleacetic Acid-induced Growth. Plant Physiol. 1980, 66, 321-325. [CrossRef] [PubMed]

52. Van Den Dries, N.; Giannì, S.; Czerednik, A.; Krens, F.A.; De Klerk, G.-J.M. Flooding of the apoplast is a key factor in the development of hyperhydricity. J. Exp. Bot. 2013, 64, 5221-5230. [CrossRef] [PubMed]

53. Tao, S.; Wang, D.; Jin, C.; Sun, W.; Liu, X.; Zhang, S.; Gao, F.; Khanizadeh, S. Cinnamate-4-Hydroxylase Gene Is Involved in the Step of Lignin Biosynthesis in Chinese White Pear. J. Am. Soc. Hortic. Sci. 2015, 140, 573-579. [CrossRef]

54. Livak, K.J.; Schmittgen, T.D. Analysis of relative gene expression data using real-time quantitative PCR and the $2-\Delta \Delta C T$ Method Methods 2001, 25, 402-408. [CrossRef]

55. Sundin, L.; Vanholme, R.; Geerinck, J.; Goeminne, G.; Höfer, R.; Kim, H.; Ralph, J.; Boerjan, W. Mutation of the Inducible ARABIDOPSIS THALIANA CYTOCHROME P450 REDUCTASE2 Alters Lignin Composition and Improves Saccharification. Plant Physiol. 2014, 166, 1956-1971. [CrossRef] [PubMed]

56. Kováčik, J.; Klejdus, B. Tissue and method specificities of phenylalanine ammonia-lyase assay. J. Plant Physiol. 2012, 169, 1317-1320. [CrossRef] [PubMed] 